Materials for Technology Students 


\title{
Materials for Technology Students
}

\author{
Vernon John \\ M.Sc., C.Eng., M.I.M.M., A.I.M. \\ Senior Lecturer in Engineering, \\ The Polytechnic of Central London
}

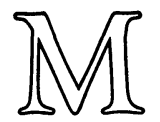


ISBN 978-0-333-17641-2 ISBN 978-1-349-02434-6 (eBook)

DOI 10.1007/978-1-349-02434-6

(C) Vernon John 1975

Reprint of the original edition 1975

All rights reserved. No part of this publication may be reproduced or transmitted, in any form or by any means, without permission.

First published 1975 by

THE MACMILLAN PRESS LTD

London and Basingstoke

Associated companies in New York Dublin

Melbourne Johannesburg and Madras

SBN 333176413

This book is sold subject to the standard conditions of the Net Book Agreement.

The paperback edition of this book is sold subject to the condition that it shall not, by way of trade or otherwise, be lent, re-sold, hired out, or otherwise circulated without the publisher's prior consent in any form of binding or cover other than that in which it is published and without a similar condition being imposed on the subsequent purchaser. 


\section{Contents}

Preface ix

List of symbols $\quad$ xi

Units xii

1. Atomic Structure and Bonding 1

1.1 Introduction - 1.2 Elementary Particles - 1.3 Atomic Number and Atomic Mass Number - 1.4 The Gram Atom and Avogadro's Number - 1.5 The

Structure of the Atom - 1.6 The Periodic Table - 1.7 Valency - 1.8 The Ionic Bond - 1.9 The Covalent Bond - 1.10 The Metallic Bond - 1.11 Secondary Bonds

2. Chemical Principles

2.1 Stoichiometric Formulae - 2.2 Reaction Equations - 2.3 Reactivity -

2.4 Energy Change in a Reaction - 2.5 Combustion and Calorific Value - 2.6

Air/Fuel Ratio - 2.7 Polymerisation - 2.8 Ionisation and Electrolysis - 2.9

Corrosion

3. Aggregates of Atoms

3.1 States of Matter - 3.2 Crystalline and Amorphous Solids - 3.3 Crystal Classes - 3.4 Identification of Planes and Directions - 3.5 Metallic Crystals 3.6 Crystalline Compounds - 3.7 Ceramics and Silicates - 3.8 The Glass State 3.9 Defects in Crystals - 3.10 Linear and Non-linear Polymer Structures

4. Elastic Behaviour

4.1 Direct Stress and Strain - 4.2 Elasticity - 4.3 Shear Stress and Shear Strain - 4.4 The Elastic Limit - 4.5 Relationships between Elastic Constants 4.6 Elastic Strain Energy - 4.7 Thermal Stresses 
5. Shearing Force and Bending Moment

5.1 Elastic Bending - 5.2 Shearing Force and Bending Moment - 5.3 Shearingforce and Bending-moment Diagrams - 5.4 Graphical Method for Bending Moment

\section{Theory of Bending}

6.1 Moments of Area - 6.2 Pure Bending - 6.3 Limitations of the Purebending Formula - 6.4 Deflection of Beams - 6.5 Slope and Deflection by Calculus - 6.6 Deflection by Strain Energy - 6.7 Slope and Deflection by the Moment-Area Method - 6.8 Deflection by a Graphical Method - 6.9 Shear Stresses in Beams

7. Theory of Torsion

7.1 Torsion of a Cylinder - 7.2 Transmission of Power - 7.3 Energy Stored in a Shaft

\section{Plastic Behaviour}

8.1 Plastic Flow in Metals - 8.2 Slip Planes - 8.3 Role of Dislocations - 8.4 Polycrystalline Metals -8.5 Work Hardening and Recrystallisation - 8.6 Solid Solution Strengthening - 8.7 Dispersion Strengthening - 8.8 Hardness and Ductility - 8.9 Behaviour of Ceramics under Stress - 8.10 Glasses - 8.11 Polymers under Stress - 8.12 Reinforced Materials

9. Phase Diagrams

9.1 Phases and Components - 9.2 The $\mathrm{H}_{2} \mathrm{O}$ Diagram - 9.3 Polymorphism 9.4 Metallic Alloy Systems - 9.5 Binary Alloy Phase Diagrams - 9.6 Precipitation Hardening - 9.7 The Iron-Carbon System

10. Electrical and Magnetic Properties

10.1 Electron Excitation - 10.2 Electron Band Structure - 10.3 Conduction in Metals - 10.4 Semiconduction - 10.5 The $p-n$ Junction - 10.6 Magnetic Domains - 10.7 The Magnetisation Curve and $B-H$ Loop -10.8 Hysteresis and Eddy-current Losses - 10.9 Dielectrics - 10.10 The Hall Effect

11. Optical, Thermal and Other Properties

11.1 The Energy Spectrum - 11.2 Absorption and Transmission - 11.3

Refraction and Polarisation - 11.4 Luminescence - 11.5 Thermal Conductivity 11.6 Thermal Expansion - 11.7 Sound Absorption and Damping - 11.8 Ultrasonics - 11.9 Interface Effects and Surface Tension - 11.10 Friction and Lubrication - 11.11 Chemical Attack and Corrosion - 11.12 Corrosion Prevention - 11.13 Irradiation of Materials 
12. Forming Processes

12.1 Introduction - 12.2 Sand Casting - 12.3 Diecasting - 12.4 Other Casting Processes - 12.5 Ingot Casting - 12.6 Hot Forging and Rolling - 12.7

Extrusion - 12.8 Fibre Structure - 12.9 Cold-forming Processes - 12.10

Moulding of Plastics - 12.11 Powder Techniques

13. Cutting Processes

13.1 Introduction - 13.2 Action of a Single-point Cutting-tool - 13.3 Machinability - 13.4 Cutting-tool Materials - 13.5 Shearing and Blanking - 13.6

Grinding

14. Joining Processes

14.1 Introduction - 14.2 Soldering and Brazing - 14.3 Fusion-welding Processes - 14.4 Structures of Weld and Heat-affected Zones - 14.5 Pressurewelding Processes - 14.6 Welding of Plastics - 14.7 Use of Adhesives

15. Materials Selection

15.1 The Selection Problem - 15.2 Forms of Supply - 15.3 Cost Aspects and Availability - 15.4 Case Studies

Appendix A Macro- and Microscopical Examination of Metals 219

Appendix B Data Tables - Table B1 Physical Properties of some Pure 224

Metals; Table B2 Comparison of Properties of Metals, Plastics and Ceramics

Index 


\section{Preface}

In recent years there have been a number of significant changes in the approach to education for engineering. One of the most important of these changes has been the recognition that the science of materials must form an integral part of any engineering course. In the past, the intensive study of materials normally commenced in Higher National or degree courses. I am very pleased to see that the subject is now introduced in its rightful place as one of the basic foundation studies in the O.N.D. in Technology course and also at G.C.E. Advanced level in engineering science courses. Unfortunately, the O.N.D. in Technology course is only to be a transient phenomenon and will shortly be superseded by the new Technician Diploma and Certificate courses. However, materials science studies will feature prominently in the new courses and technician students should find the style and content of this book suitable for them.

In this book I have used a largely descriptive approach to the very broad subject of materials which should be suitable for students with a background of G.C.E. Ordinary-level science. Some knowledge of differential and integral calculus is needed for the work on elementary stress analysis, but by the time this stage of the materials course is reached the student should be conversant with these techniques from his complementary studies in mathematics.

A number of test questions have been placed at the ends of chapters 5, 6 and 7, the stress analysis section. I have not included revision questions for other chapters because, in very many instances, colleges choose to examine at O.N.D. level by means of multiple-choice objective tests.

I wish to record my gratitude for the help and advice received from colleagues and family during the preparation of this book, in particular Clive Beesley and Ed Drabble of P.C.L. for reading the manuscript and suggesting improvements. I am greatly indebted to my wife for reducing my untidy handwriting to a clean typescript, to my elder son Roger for invaluable assistance in proof reading, and to my younger son Derek for not interrupting too often while the work was in progress.

Vernon John 


\section{List of Symbols}

Quantity

Atomic number

Atomic mass number (atomic weight)

Avogadro's number

Planck's constant

Temperature

Thermal conductivity

Universal gas constant

Frequency

Direct stress

Direct strain

Shear stress

Shear strain

Young's modulus of elasticity

Modulus of rigidity

Bulk modulus of elasticity

Poisson's ratio

Force

Bending moment (moment of force)

Second moment of area

Polar second moment of area

Torque

Power

Elastic strain energy

Time

Glass transition temperature

Surface tension

Velocity of light
Symbol

$Z$

$M$

$N_{\mathrm{A}}=6.023 \times 10^{23}$ (molecules per mole)

$h=6.625 \times 10^{-34} \mathrm{JS}$

$T$ or $\theta$

$k$

$R_{0}=8.314 \mathrm{~kJ} / \mathrm{kmol} \mathrm{K}$

$\nu$ (Greek nu)

$\sigma$ (Greek sigma)

$\epsilon$ (Greek epsilon)

$\tau$ (Greek tau)

$\gamma$ (Greek gamma)

E

G

K

$\nu$

F

$M$

$I$

$J$

T

$P$

$U$

$t$

$T_{\mathrm{g}}$

$\gamma$

$c=3 \times 10^{8} \mathrm{~m} / \mathrm{s}$ 


\section{Units}

The units used through this book conform to the SI system. The principal units that are quoted in the text are given below. (Since we are in the change-over period, the Imperial equivalents of some SI units are listed.) Preferred SI units are printed in bold type.

Quantity

Mass

Length

Time

Velocity

Temperature

Amount of substance

Plane angle

Area

Volume

Density

Force

Unit

Symbol

kilogram
gram
tonne

metre

millimetre

second

minute

hour

metre per second

degree Kelvin

degree Celsius

mole

kilomole

radian

degree

square metre

square millimetre

cubic metre

cubic millimetre

kilogram per cubic metre

newton

kilonewton

meganewton $\mathrm{kg}(1 \mathrm{~kg}=2.205 \mathrm{lb})$

$\mathrm{g}$

$\mathrm{t}(\mathrm{Mg})(1 \mathrm{t}=1000 \mathrm{~kg}=$ 0.984 ton)

m $(1 \mathrm{~m}=39.37$ in. $)$

$\mathrm{mm}$

$\mathbf{s}$

$\min$

$\mathrm{h}$

$\mathrm{m} / \mathrm{s}$

$\mathrm{K}$

${ }^{\circ} \mathrm{C}$

mol

$\mathrm{kmol}$

$\operatorname{rad}\left(1 \mathrm{rad}=180^{\circ} / \pi\right)$

$\mathrm{m}^{2}$

$\mathrm{mm}^{2}$

$\mathrm{m}^{3}\left(1 \mathrm{~m}^{3}=35.315 \mathrm{ft}^{3}\right)$

$\mathrm{mm}^{3}$

$\mathrm{kg} / \mathrm{m}^{3}\left(1 \mathrm{~kg} / \mathrm{m}^{3}=1000\right.$ $\left.\mathrm{g} / \mathrm{cm}^{3}=0.062 \mathrm{lb} / \mathrm{ft}^{3}\right)$

$\mathrm{N}(1 \mathrm{~N}=0.225 \mathrm{lbf})$

$\mathrm{kN}$

MN 
Quantity

Moment of force

(Torque)

Stress (pressure)

Surface tension

Energy

Calorific value (mass)

Calorific value (volume)

Thermal conductivity

Power

Second moment of area

Electric current

Voltage

Quantity of electricity

Electrical resistance

Electrical resistivity

Magnetic flux

Magnetic flux density

Frequency
Unit

Symbol

newton metre

kilonewton metre

newton per square metre

meganewton per square

metre

giganewton per square

metre

bar

newton per metre

joule

electron volt

megajoule per kilogram

megajoule per cubic

metre

watt per metre per degree Kelvin

watt

kilowatt

metre to the fourth

millimetre to the fourth

ampere

volt

coulomb

ohm

ohm metre

weber

tesla

hertz
$\mathrm{Nm}(1 \mathrm{Nm}=0.738 \mathrm{lbf} \mathrm{ft})$

$\mathrm{kNm}$

$\mathrm{N} / \mathrm{m}^{2}\left(1 \mathrm{~N} / \mathrm{m}^{2}=0.000145\right.$

$\left.\mathrm{lbf} / \mathrm{in}^{2}\right)$

$\mathrm{MN} / \mathrm{m}^{2}\left(1 \mathrm{MN} / \mathrm{m}^{2}=0.102\right.$

$\mathrm{kgf} / \mathrm{mm}^{2}=0.0648$ tonf $\left./ \mathrm{in}^{2}\right)$

$\mathrm{GN} / \mathrm{m}^{2}$

bar or b $\left(1 \mathrm{bar}=10^{5} \mathrm{~N} / \mathrm{m}^{2}\right)$

$\mathrm{N} / \mathrm{m}$

$\mathbf{J}(\mathrm{Nm})$

$\mathrm{eV}\left(1 \mathrm{eV}=1.602 \times 10^{-19} \mathrm{~J}\right)$

$\mathrm{MJ} / \mathrm{kg}(1 \mathrm{MJ} / \mathrm{kg}=429.5$

$\mathrm{Btu} / \mathrm{lb})$

$\mathrm{MJ} / \mathrm{m}^{3}\left(1 \mathrm{MJ} / \mathrm{m}^{3}=26.81\right.$

$\mathrm{W} / \mathrm{m} \mathrm{K}$ $\left.\mathrm{Btu} / \mathrm{ft}^{3}\right)$

$\mathrm{W}(\mathrm{J} / \mathrm{s})$

$\mathrm{kW}(1 \mathrm{~kW}=1.342 \mathrm{hp})$

$\mathrm{m}^{4}$

$\mathrm{mm}^{4}$

A

V

C (As)

$\Omega(\mathrm{V} / \mathrm{A})$

$\Omega \mathrm{m}$

$\mathrm{Wb}(\mathrm{Vs})$

$\mathrm{T}\left(\mathrm{Wb} / \mathrm{m}^{2}\right)\left(1 \mathrm{~T}=10^{4}\right.$ gauss $)$

$\mathrm{Hz}\left(\mathrm{s}^{-1}\right)$ 